\title{
Resilience and Vulnerability: Complementary or Conflicting Concepts?
}

\author{
Fiona Miller $^{1}$, Henny Osbahr ${ }^{2}$, Emily Boyd $^{3,4}$, Frank Thomalla $^{5,6}$, Sukaina Bharwani $^{7}$, Gina Ziervogel ${ }^{7,8}$, \\ Brian Walker $^{4,9}$, Jörn Birkmann ${ }^{10}$, Sander van der Leeuw ${ }^{11}$, Johan Rockström ${ }^{4,12}$, Jochen Hinkel ${ }^{13}$,

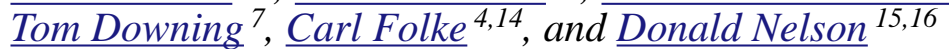

\begin{abstract}
Resilience and vulnerability represent two related yet different approaches to understanding the response of systems and actors to change; to shocks and surprises, as well as slow creeping changes. Their respective origins in ecological and social theory largely explain the continuing differences in approach to social-ecological dimensions of change. However, there are many areas of strong convergence. This paper explores the emerging linkages and complementarities between the concepts of resilience and vulnerability to identify areas of synergy. We do this with regard to theory, methodology, and application. The paper seeks to go beyond just recognizing the complementarities between the two approaches to demonstrate how researchers are actively engaging with each field to coproduce new knowledge, and to suggest promising areas of complementarity that are likely to further research and action in the field.
\end{abstract}

Key Words: climate change; hazards; interdisciplinarity; resilience; social-ecological systems; vulnerability

\section{INTRODUCTION}

Resilience and vulnerability, as well as the related concepts of adaptation and transformation, are central concepts in highly influential but somewhat different ways of framing our analyses of socialecological change and the challenges of sustainability (MA 2005, Janssen and Ostrom 2006, IPCC 2007, Jäger et al. 2007, Schneider et al. 2007). Although these four concepts are related, in this paper, we focus in particular on resilience and vulnerability. Our underlying hypothesis is that a number of fundamental linkages and complementarities exist between the two approaches, but that they have been kept artificially separate by conceptual constructs, scientific traditions, and lack of interaction between the two academic communities involved. Considering the urgency of the challenges posed by environmental change, we no longer have the luxury of pursuing purely curiosity-driven conceptual advances in the study of common problems along parallel tracks. While still acknowledging the value of multiple perspectives, to address pressing real world problems we need to be better at identifying convergence, seeking collaboration to advance integrated socialecological knowledge, and building on the strengths from different fields.

To further such convergence, it is imperative that scholars critically reflect on the core concepts involved, as well as on the ways to use them and the toolkits they derive from them, to ascertain their appropriateness in explaining and addressing the issues at hand. This paper seeks to advance that goal. The authors argue that, taken singly, each approach and each research community has so far fallen short of meeting the needs of sustainable development, and although interest is rising in policy they remain largely disconnected from practice. This is evidenced by the continued lack of integration of resilience and vulnerability assessment methods and insights into major national and international policy and planning initiatives, beyond isolated

\footnotetext{
${ }^{1}$ Department of Resource Management and Geography, University of Melbourne, ${ }^{2}$ School of Agriculture, Policy and Development and the Walker Institute for Climate Systems Research, University of Reading ${ }^{3}$ Sustainability Research Institute, University of Leeds, ${ }^{4}$ Stockholm Resilience Centre, Stockholm University, ${ }^{5}$ Stockholm Environment Institute (Asia), ${ }^{6}$ Department of Environment and Geography - Human Geography, Macquarie University, ${ }^{7}$ Stockholm Environment Institute (Oxford), ${ }^{8}$ Climate Systems Analysis Group (CSAG), University of Cape Town, ${ }^{9}$ CSIRO Sustainable Ecosystems, Australia,

${ }^{10}$ Institute for Environment and Human Security, United Nations University, ${ }^{11}$ School of Human Evolution and Social Change, Arizona State University,

${ }^{12}$ Stockholm Environmental Institute (Sweden), ${ }^{13}$ Potsdam Institute for Climate Impact Research, ${ }^{14}$ The Beijer Institute, Stockholm University, ${ }^{15}$ Tyndall

Centre for Climate Change Research, University of East Anglia, ${ }^{16}$ Department of Anthropology, University of Georgia
} 
cases in ecosystem management, disaster management, and climate change adaptation. Theoretical approaches and practical applications proposed by either community often do not refer to work of the other community, and there are few documented examples of operational tools that may induce positive moves toward collaboration between the communities and the articulation of their ideas.

However, we are convinced that, together, the communities can go some considerable way in addressing the needs of research on the challenges presented by social-ecological change, and in providing a more holistic and integrative approach to the study of sustainability. To achieve that, researchers have the responsibility to share experiences and insights on a core set of common conceptual and methodological principles, which can guide investigations and the development of methods for future management and governance, and to focus on what they can collectively provide to organizations and institutions working to address the consequences of social and environmental change.

Here, we aim to explore the potential areas of convergence to identify key synergies in theory, methodology, and application. Moreover, we seek to demonstrate how some researchers from the two communities are actively engaging in the coproduction of new knowledge (see Miller et al. $2008 b$ ). We illustrate this with specific examples, and examine how the concepts are used in practice in the operational realms of planning, management, and governance. In doing so, we identify the limits and opportunities for integration of the resilience and vulnerability approaches.

A major difficulty in pinpointing similarities and differences between the two approaches is caused by the use of the terms "resilience" and "vulnerability" to refer to three distinct elements: (1) the concepts themselves and their associated theories, (2) the methodologies used for assessing the concepts, and (3) the "real-world" practice of addressing social-ecological change in planning, management, and governance. We attempt to avoid this confusion by explicitly naming the elements to which we refer, whether to: the concepts, in the narrow sense as used in definitions, conceptualizations, and theories; methodology, in terms of the sets of methods that are applied for assessing the concepts; or the usage of concepts, theories, and methods for addressing real-world problems in practice. Finally, by approach, we refer to the collection of concepts, theories, methodologies, and practice. The paper is organized with respect to these distinctions.

\section{KEY INSIGHTS ON THEORY}

The different epistemological traditions in the natural and social sciences from which the two communities stem largely explain the different emphases, interpretations, and approaches taken by researchers working in the resilience and vulnerability traditions. Each of these communities has differentially emphasized either the ecologicalbiophysical or the social-political dimensions of problems under investigation. Broadly speaking, there is an epistemological distinction between positivist and constructivist approaches. Although this distinction is not absolute, resilience research has generally been more strongly influenced by a positivist epistemology, arguing that phenomena can be objectively defined and measured. Some elements of vulnerability research also adopt a positivist approach, yet in this domain there is considerable work in the constructivist tradition (McLaughlin and Dietz 2007) in which the subjective world of diverse human perceptions, values, cultures, agency, and ontologies is explored. This epistemological tension has been a contributing factor to the absence of an easy exchange of ideas and experiences between researchers from the two communities, hindering interdisciplinary collaboration. The discussion below outlines key underlying concepts and disciplinary contributions, and how each field conceptualizes systems and change in different ways. This section concludes by demonstrating that increasingly we can observe a move toward genuinely integrated approaches that recognize the value of diverse epistemologies (see Miller et al. $2008 c$ ).

\section{Distinct disciplinary origins}

The epistemic and disciplinary contributions to resilience theory in relation to social-ecological systems (SES) have primarily come from the natural sciences, and in particular ecology (see Folke 2006, Gallopín 2006). While acknowledging contributions stemming from social scientists working on common property resources management (Berkes and Folke 1998, Berkes et al. 2003), it is only 
relatively recently that the disciplinary contributions to resilience theory have significantly diversified and more integrated approaches been explored. However, as Adger (2000) notes, the concept of resilience cannot be uncritically transferred from the natural to the social sciences, and has triggered the exploration of more integrated approaches.

The vulnerability community, by contrast, is more diverse in terms of disciplinary and cultural contributions, with considerable internal tensions and debates (Oliver-Smith 1996, Alwang et al. 2000, Adger 2006, McLaughlin and Dietz 2007). Vulnerability research has been shaped by theoretical traditions in hazard studies in the geophysical sciences, human ecology, political economy, constructivism, and political ecology (Eakin and Luers 2006, McLaughlin and Dietz 2007). Political ecology has been particularly influential, providing a strong critique of the technocratic focus of earlier geophysical approaches, perspectives that continue, to some extent, to influence climate change and hazards research. Arguably, political ecology and recent work in sustainability science that crosses over into resilience research (see Turner et al. 2003) provide the most integrated perspectives.

\section{Defining concepts: responses to stress}

Both communities have an overriding concern with the response of systems to stress or perturbations. Resilience has been used in two ways in ecology, one focusing on recovery and return time following a disturbance, the other focusing on how much a system can be disturbed and still persist without changing function. There has been a shift in emphasis from the former, termed "engineering" resilience, to the latter (Holling 1996), and in the last decade the resilience lens has broadened its application to social-ecological systems (Berkes and Folke 1998, Gunderson and Holling 2002), emphasizing three critical features of resilience: persistence, adaptability, and transformability (Walker et al. 2004, Folke 2006). Resilience is often defined in terms of the ability of a system to absorb shocks, to avoid crossing a threshold into an alternate and possibly irreversible new state, and to regenerate after disturbance (Resilience Alliance 2009). This widening of the concept of resilience has brought within its scope the role of institutions, social capital, leadership, and learning. For example, the work of Olsson et al. (2004) on adaptive governance in an agro-ecological landscape in southern Sweden highlights the role of leadership, vision, and organization in contributing to a transformation of the local wetlands to a more desirable social-ecological state. A wider resilience lens is also being applied to institutional responses to climate change effects and to climate solutions in livelihood transformations (Boyd et al. 2008, Boyd and Osbahr 2010).

A further distinction in conceptualizing SES resilience is made between "specified" and "general" resilience. Specified resilience is about the resilience "of what, to what" (Carpenter et al. 2001), for example, the productivity of specific ecosystem services, e.g., grass for livestock, in relation to particular threats, e.g., fire, and concerns the potential of variables to exhibit threshold effects that may lead to regime shifts, i.e., a sudden change from one state to another. General resilience concerns the resilience of all aspects of a system to unspecified, including novel and unforeseen, disturbances (Resilience Alliance 2009). Both are important because attempting to make a system more resilient in a particular way, for example, to low rainfall, may inadvertently result in it becoming less resilient in other ways, for example, to salinity. Thus there is a need for managers to balance a concern for specified and general resilience.

The broadening of the concept of resilience, particularly in relation to SES, has resulted in a tension between the stress on the persistence of a system in its current state and transformation to a fundamentally new system state often viewed as more 'desirable'. This is particularly apparent when considering the social responses to climate change. Although it is important to understand the characteristics that support adaptation, the maintenance of current societies and economies and their particular coping responses, there is a growing recognition that the persistence of certain social and economic conditions hampers positive long term consequences in terms of sustainability and social equity. Thus research into specified resilience of rural communities to climate variability in southern Africa (Thomas et al. 2007, Osbahr et al. 2008), for example, identified that just maintaining agricultural coping strategies may suppress innovation, reinforce poverty, and prevent the community from being able to address the more complex feedbacks within the social-ecological system. The research has shown that processes of social learning and communication across multiple institutional scales, 
community reorganization, and adaptive capacity are critical when building general resilience of marginal societies to climate change (Osbahr et al. 2008). The question of the desirability of particular system states also broadens the scope of inquiry to consideration of how costs and benefits are socially differentiated over time, a question central to much vulnerability research.

There are many meanings of vulnerability in different contexts, often focusing particularly on socio-political systems (see www.wikiADAPT.org for a selection of vulnerability definitions). Vulnerability is applied as a core concept in disaster risk (Burton et al. 1978, Hewitt 1983, 1997, Blaikie et al. 1994, Oliver-Smith 1996, Wisner et al. 2004), in the study of livelihoods and poverty (Chambers 1989, Chambers and Conway 1992, Prowse 2003), food security (Sen 1981, Watts 1983, Watts and Bohle 1993, Bohle et al. 1994), and climate change (Klein and Nicholls 1999, Kelly and Adger 2000, Barnett 2001, 2003, Downing et al. 2001). Adger (2006), Gallopín (2006), and Kasperson et al. (2005) identify, amidst the diverse interpretations of vulnerability, the key concepts of exposure, sensitivity, coping, and adaptive capacity as underpinning many dominant approaches. Furthermore, Downing et al. (2005) identify the following common elements of most approaches to vulnerability: the threat, e.g., climate change; a place or sector, e.g., health outcomes; a socioeconomic group, e.g., the poor; and the consequences or outcomes of vulnerability, e.g., loss of livelihood. A meta-analysis of vulnerability definitions confirms these findings and adds the further element of preference criteria to evaluate the negative extent of the outcome (Ionescu et al. 2009).

There is an ongoing debate on how to characterize vulnerability in both theory and practice (e.g. Birkmann 2006, Ionescu et al. 2009). Increasingly, it is seen as a condition, encompassing characteristics of exposure, susceptibility, and coping capacity, shaped by dynamic historical processes, differential entitlements, political economy, and power relations, rather than as a direct outcome of a perturbation or stress (Blaikie et al. 1994, Downing et al. 2005, Eakin and Luers 2006). For instance, a combination of the processes of economic liberalization, climate change, and other environmental dynamics have been shown to interact with socio-political factors to influence human vulnerability (O'Brien and Liechenko 2001).
Although the abovementioned approaches to vulnerability differ in their framing and scale of analysis, their starting point is similar: they look at how various social groups or communities exposed to shocks and stressors are, potentially, effected, and how they differ in terms of their sensitivity and coping capacity, with an emphasis on how spatial, physical, and social characteristics influence vulnerability. In contrast to the adaptation community, vulnerability researchers predominantly focus on the response to hazards or shocks, rather than on longer term adjustments and changes. However, as Nelson et al. (2007) point out, adaptation measures often fail to address persistent and intractable vulnerabilities, thus undermining their success and sustainability.

Recent meta-analyses of vulnerability concepts and methodologies have shown that, in the studies reviewed, there was often little coherence between the theoretical definitions and the methodologies applied, while authors often paid lip-service to the concepts of resilience and vulnerability (Hinkel 2008, Zou and Thomalla 2008, Ionescu et al. 2009, Larsen et al. 2009). Many assessments, for example, use the Intergovernmental Panel on Climate Change definition of vulnerability (IPCC 2001), but end up applying very different kinds of methodologies (Hinkel 2010). In their meta-analysis of social vulnerability to coastal hazards in South and Southeast Asia, Zou and Thomalla (2008) identified a gap between theoretical work on vulnerability and empirically based case studies in which the application of, or even reference to, particular conceptual frameworks is rare. Of the 128 documents analyzed, only $14 \%$ referred to a particular conceptual framework for vulnerability assessment. Although this is not the case with all work in the field, it is certainly worrying that such a high incidence of empirical work exists that is not well linked to conceptual development. Similar trends can be seen in the resilience literature, in which empirical work is still interpreting resilience in the narrow sense of return time and recovery, thereby missing the broader use of the concept.

The many definitions and approaches to vulnerability reveal the multifaceted nature of the problems under inquiry, such as access to resources, predisposition to harm, poverty, and their persistence. Moreover, this diversity of approaches and definitions reflects the different purposes and scope of vulnerability analysis in different domains, which can range from a structured, analytical 
assessment of community based adaptation to climate change, to advocacy for marginalized communities (Hinkel 2010).

\section{System and actor dynamics}

Both the resilience and vulnerability approaches are concerned with how systems respond to change. However, each approach considers systems in quite different ways. Nelson et al. (2007) observe that the resilience community tends to prefer a systemic approach (see also Olsson et al. 2006, Walker et al. 2006), whereas the climate change adaptation and the vulnerability communities tend to take an actororiented approach (see also Wisner et al. 2004, McLaughlin and Dietz 2007). The complex systems approach adopted by many resilience theorists emphasizes the complexity of social, ecological, and geophysical systems, and conceptualizes them in terms of multiple interacting agents and relationships (Ramos-Martin 2003). Hence, resilience has advanced our understanding of system dynamics and interconnections, ecological thresholds, social-ecological relations, and feedback loops. The system as it is presented in vulnerability studies, on the other hand, is often understood in terms of a unit of analysis such as a humanenvironment system or a catchment system, or a social group, livelihood, or sector, rather than considered in terms of its component parts and interacting relations. The types of processes and dynamics that are investigated are more likely to be social, political, and economic rather than biophysical and ecological. Both approaches may be concerned with slow variables or drivers of change, yet it is still the case that biophysical variables tend to be the focus within resilience research, and historical and political economic processes in vulnerability research. An actororiented view, so often adopted in vulnerability studies, addresses the interests, values, knowledge, and agency of actors, allowing examination of issues of power, social change, access, entitlements, conflict, and equity, issues critical to matters of SES management and governance. Although such issues have not been at the center of resilience thinking, the resilience lens implicitly deals with them in the context of the management and governance of resources and ecosystem services in dynamic landscapes and seascapes. We argue, as do Nelson et al. (2007), that the two approaches are potentially complementary, in the sense that actor-based analyses look at the processes of negotiation, decision making, and action, whereas systemsbased analyses complement this approach by examining the interaction of social and ecological processes.

Both approaches focus on the interaction of slower and more rapid dynamics. The disaster risk reduction community has struggled to conceptualize changes in societal vulnerability to both shock events and long term climate effects, while also considering the consequences of short term actions on longer term social-ecological resilience (Venton and La Trobe 2008). The resilience approach recognizes the dynamic interplay between periods of incremental change and periods of abrupt change, emphasizing that such dynamics, often nonlinear and surprising, are an inherent part of any system (Berkes et al. 2003, Walker and Salt 2006). The challenge from a resilience perspective is to learn to live with change and develop the capacity to deal with it instead of trying to block it out, which has been shown to lead to system-wide vulnerability. The resilience literature often refers to the latter as the pathology of natural resource management (Holling and Meffe 1996). Subsidies and safety nets, e.g., credit, may generate a comparable pathology in social systems because they are not always transparent or visible and may entrench existing power structures, dependencies, and even poverty. Changes and shocks in social-ecological systems will always cause vulnerability to some, making it necessary to identify acceptable levels of vulnerability and to maintain the ability to respond (Nelson et al. 2007). This raises important questions as to who defines what acceptable levels of vulnerability might be and for whom, and how such questions are addressed.

Vulnerability research generally seeks to understand the underlying causes of vulnerability, the scale at which it occurs, and the main actors involved, to identify opportunities for risk reduction, coping, and adaptation. Many studies, although focusing on a major event like a natural disaster, famine, or epidemic, tend to focus on the interaction between historical and contemporary processes that may result in situations in which certain groups, regions, or sectors are more vulnerable to the effects of such events than others. However, what is often neglected, unlike in resilience research, are the interactions between longer term and shorter term ecological and biophysical changes. Likewise, resilience approaches aimed at securing future sustainability cannot be 
realized without understanding the socio-political processes and environmental linkages that underpin the foundations of vulnerability. Integrated assessments that consider both aspects are therefore required to underpin more sustainable livelihood strategies and more adaptive governance, particularly those that offer reflection on assessing options within a changing context of social acceptability and experience.

\section{Reinterpretations and misunderstandings}

Although each community shares a similar lexicon, concepts are often imbued with different meanings. Interpretations of vulnerability within the resilience community have tended to focus on the physical vulnerability of ecosystems and ecosystem functions and services, rather than taking an integrated perspective. Nyström et al. (2000) and Nyström and Folke (2001), for example, explore the vulnerability of elements of coral reefs, and Carpenter et al. (1998) consider aquatic systems. Likewise, narrow interpretations of resilience in the vulnerability research community have tended to stress social aspects such as access to assets, social support systems, networks, institutions, and learning (Chambers and Conway 1992, Smith 1992, UN ISDR 2005, Cannon 2008), rather than the interconnections between social and ecological systems. An exception is Adger (2000), who explores the interconnections between ecosystem resilience and social resilience, focusing, for example, on resource dependency and institutions.

Despite a history of little dialogue among researchers in the fields of resilience, vulnerability, and adaptation, as documented by Janssen et al. (2006) and Janssen (2007), there is currently growing engagement between both communities. Miscommunications and misunderstandings, however, persist both in the semantic and the epistemic arenas. There remains some conceptual fuzziness, as well as overlap, for example, in the use of key terms and concepts within each field (Gallopín 2006). A common interpretation of vulnerability, for example, is that it is the antonym of resilience (Folke et al. 2002). "A vulnerable social-ecological system has lost resilience" (Folke 2006:262). Whereas in the Turner et al. (2003) framework for vulnerability analysis, resilience is not considered the flipside of vulnerability, but rather one of three dimensions of vulnerability, the other two being exposure and sensitivity. Logically, one can therefore have high resilience, but if exposure and sensitivity are high, then a system is nevertheless considered vulnerable.

This tendency for each research community to redefine other communities' terms in their own language, invariably situating their own concepts on a higher ground and the other's as derivative, may have impeded collaboration. While acknowledging that the many definitions of resilience and vulnerability can also hinder practice, conceptual fuzziness is not necessarily wholly negative, because such diversity can fuel debate and innovation, and is part of any process of conceptual development. We argue, as others have (Birkmann 2006, Eakin and Luers 2006, Gallopín 2006), that working toward a common lexicon would be helpful, allowing easier interdisciplinary collaboration and better engagement with communities outside academia.

\section{Potential for conceptual convergence?}

As discussed, there are obvious synergies in approaches to the study of responses to stress, the interaction of slow and rapid change, and system and actor dynamics. Moreover, a degree of convergence is present around exploring ecological, institutional, and livelihood diversity, and its role in buffering shocks (Perrings et al. 1995, Adger 1999, Lavorel 1999, Ellis 2000, Berkes et al. 2003, Folke et al 2003, Berkes and Seixas 2005), as well as a common concern for issues of scale and cross-scale processes (Wisner and Luce 1993, Peterson et al. 1998, Stephen and Downing 2001, Leichenko and O'Brien 2002, Turner et al. 2003). It is clear that governance is rapidly becoming a more central concern to each field (Folke et al. 2005, Olsson et al. 2006). However, it is often interpreted in an apolitical sense in resilience research in contrast to the more politically nuanced understanding of social change and equity present in much vulnerability research (see Watts 1983, Blaikie et al. 1994, OliverSmith 1996, Pelling 1999). Climate change in particular has raised the multifaceted nature and sensitivity of issues such as the distribution of effects, negotiation of costs, and sharing of burdens, as well as the appropriateness of institutions and market instruments and other challenging governance issues concerning equity, efficacy, transparency, and accountability (Boyd et al. 2008).

In recent years, resilience research has increasingly focused on the social dimensions of dealing with 
disturbances such as transformation (Olsson et al. 2006). A recent initiative brings together a concern for vulnerability, resilience, and transformation together in the concept of ecosystem stewardship (Chapin et al. 2009). Concomitantly, vulnerability research has increasingly considered the interconnections among social, ecological, and geophysical systems (Turner et al. 2003, O'Brien et al. 2009), and has integrated complex physical system dynamics. ${ }^{[1]}$ This progressive social-ecological convergence of the two areas of investigation opens many opportunities for conceptual and methodological synergy and potentially some overlap. Table I summarizes some distinct contributions from each field, as well as complementarities and areas coevolving according to key analytical concepts.

\section{KEY INSIGHTS ON METHODOLOGY}

Though obvious differences in analytical framing remain notwithstanding the recent trend toward convergence, when considering what researchers are actually doing, the methodologies that guide them, and the tools they apply, some important similarities and crossovers are apparent. Both approaches are very broad, encompassing many and very diverse methodological elements ranging from analytical methods such as modeling (Hinkel 2008) to participatory and action research (Tschakert 2007, Archer et al. 2008, Ziervogel and Taylor 2008). Despite this diversity, both approaches rely on many similar methodological elements, even though this is often difficult to recognize because of the use of different terminologies and poor descriptions of methodologies.

\section{Hybrid, mixed methodologies}

As a sign of the growing awareness of the integrated nature of the problems under analysis, more pluralistic methodologies are emerging in both fields. This is not unique to resilience and vulnerability research, but a characteristic of other fields working at the society-nature interface, such as political ecology or ecological economics (Norgaard 1989, Rocheleau 1995, 2008). Methodological innovations are being applied in the study of social-ecological change, emerging from disciplines as diverse as computer science, i.e., multiagent models; agriculture; development studies, i.e., participatory assessment and mapping; as well as strategic studies and economics, i.e., scenario planning (Bharwani et al. 2005, Nelson et al. 2009, West 2009).

Increasingly hybrid approaches are chosen by researchers in the fields of resilience and vulnerability, spanning qualitative and quantitative traditions and including stakeholder engagement, action research, and social learning. Such a hybrid approach is exemplified by the work of Ziervogel et al. (2006a) who explore local adaptation strategies to climate variability in the context of multiple social and environmental stresses. The authors see the combination of quantitative, i.e., surveys, knowledge elicitation tools, participatory tools, and qualitative approaches, i.e., focus groups, individual interviews, participatory techniques, as helping provide a more holistic picture of the environmental and socioeconomic stresses and of individual actions and decision making processes (Ziervogel et al. 2006a). Such approaches are also more successful than single method approaches in accessing the perspectives of the most vulnerable groups in society.

Moreover, a single stress, one-scale, snapshot approach would miss much of the detail that can be captured using integrated and dynamic frameworks that allow for the emergence of unpredictable, nonlinear outcomes. One example of an innovation in the field that contributes to the goal of integration is agent-based modeling (ABM), a technique with which one can simulate complex narratives over time from different actor-oriented perspectives. Much of what is interesting to ABM researchers in the sustainability field is also that which interests vulnerability and resilience scientists, i.e., that which emerges from a close coupling of each agent to its natural and social environments, producing nonlinearity, indeterminacy, and path dependency while incorporating risk, perceptions, and imperfect information. By highlighting emergent properties, 'surprises,' or new vulnerabilities, such holistic models can allow the formulation of 'better' questions for empirical work targeting gaps in the understanding of interdisciplinary domains.

\section{Similar themes, yet different questions}

Though similar themes and problems may be addressed by resilience and vulnerability researchers, they often adopt different starting points, guiding questions and frameworks that, 
Table 1. Conceptual contributions and areas of convergence between resilience and vulnerability theory. $\mathrm{SES}=$ social-ecological systems.

\begin{tabular}{|c|c|c|c|}
\hline Analytical Concept & Resilience & Vulnerability & $\begin{array}{l}\text { Contribution to } \\
\text { Integration }\end{array}$ \\
\hline $\begin{array}{l}\text { Integrated social- } \\
\text { ecological analyses }\end{array}$ & $\begin{array}{l}\text { Move from ecological toward } \\
\text { social dimensions within coupled } \\
\text { SES; social often considered } \\
\text { secondary; }\end{array}$ & $\begin{array}{l}\text { From social to coupled SES or } \\
\text { human-environment systems; still } \\
\text { rare to truly integrate ecological } \\
\text { processes. }\end{array}$ & Complementary \\
\hline Approach to system & Systems thinking & Unit of analysis & Complementary \\
\hline $\begin{array}{l}\text { Slow versus fast } \\
\text { variables of change }\end{array}$ & Core & $\begin{array}{l}\text { Core (understood as shocks and } \\
\text { stresses) }\end{array}$ & Complementary \\
\hline Multiple stressors & Multiple variables & Core & $\Leftarrow$ Contribution \\
\hline Scale & $\begin{array}{l}\text { Core; Physical units from local to } \\
\text { global }\end{array}$ & $\begin{array}{l}\text { Core: Usually social units from local } \\
\text { to global, or geophysical units, e.g., } \\
\text { a watershed }\end{array}$ & Complementary \\
\hline Alternate stable states & Core & $\begin{array}{l}\text { Weak, except in terms of livelihood } \\
\text { or governance strategies. }\end{array}$ & $\Rightarrow$ Contribution \\
\hline $\begin{array}{l}\text { Social-ecological } \\
\text { feedbacks }\end{array}$ & Core & Weak & $\Rightarrow$ Contribution \\
\hline Thresholds & $\begin{array}{l}\text { Core (understood primarily as } \\
\text { physical) }\end{array}$ & Rare & $\Rightarrow$ Contribution \\
\hline Adaptation & Core & Core & Complementary \\
\hline Transformation & Core & $\begin{array}{l}\text { Weak, except in terms of } \\
\text { livelihoods. Rarely is attention given } \\
\text { to the processes enabling or } \\
\text { underlying transformation. }\end{array}$ & $\Rightarrow$ Contribution \\
\hline Adaptive management & Core & Core & Jointly evolving \\
\hline Perturbations & Core & Core & Complementary \\
\hline Agency & Weak & Core & $\Leftarrow$ Contribution \\
\hline
\end{tabular}




\begin{tabular}{|c|c|c|c|}
\hline Risk reduction & Weak & Core & $\Leftarrow$ Contribution \\
\hline Empowerment & Weak & Core & $\Leftarrow$ Contribution \\
\hline Learning & Core & Emerging & Jointly evolving \\
\hline $\begin{array}{l}\text { Different knowledge } \\
\text { systems }\end{array}$ & Core & Core & Complementary \\
\hline $\begin{array}{l}\text { Operationalization, } \\
\text { implementation }\end{array}$ & Emerging & $\begin{array}{l}\text { Advanced (development of tools for } \\
\text { decision makers, practitioners) }\end{array}$ & $\Leftarrow$ Contribution \\
\hline
\end{tabular}

importantly, lead to different emphases in data collection, interpretation, and communication.

These different emphases are seen in two studies in Limpopo Province, South Africa, which were undertaken in a similar area with one starting from the vulnerability perspective (Ziervogel et al. $2006 b$, Ziervogel and Taylor 2008) and the other from the resilience perspective (Biggs et al. 2007). In the vulnerability study, the aim was to understand how different stakeholders view their vulnerability to support decision making at the village and municipal scales in Sekhukhune District. The starting point was to explore local priorities and knowledge through both qualitative and quantitative methods that engaged with individuals at the village and municipal scale. The fieldwork data were fed into an agent-based model that focused on policy options that integrated village social dynamics as well as district economic activities and was used to inform further stakeholder dialogues.

In the resilience study, the aim was to establish an overall picture of system function, including qualitative system dynamics and vulnerability analysis, in the Sand river subcatchment using resilience theory. The starting point was to build on and refine existing expert understanding of the system from data and literature. The next step was to include new input from experts. The intention was that local perceptions would be captured in existing data. This study made explicit the linkages between the social and ecological system on the one hand, and the time scales at which certain drivers proved more important than others. The vulnerability approach placed more emphasis on agency and on the identification of hooks for responding to adaptation and development challenges.

Considering how the objectives and subjects of analysis implicit in the two approaches led to different analytical tools, scales, and indicators of interest, to realize a truly integrated approach to the study of social-ecological change, this difference needs to be acknowledged and addressed so that a more balanced analysis emerges. Collaborations that enable resilience and vulnerability researchers, together with relevant stakeholders, to jointly identify key research questions would further allow such integration to occur, and allow the perspectives of diverse stakeholders, including the most vulnerable, to be captured.

\section{Bifocals: long and short temporal scales and drivers of change}

Both resilience and vulnerability approaches are concerned with multiscale temporal processes. As elaborated on in the concept of panarchy (Gunderson and Holling 2002), resilience studies seek to investigate the interaction between longer term, slow changes and drivers of change, such as climate change, and rapid changes, such as flooding, a sudden change in political leadership, or an economic crisis etc. Vulnerability analysis, with its focus on human agency and hazards, tends to focus on much shorter time frames, and, despite its concern with the underlying causes of vulnerability, few longitudinal or historical studies of vulnerability exist. However, some studies have been conducted that attempt to incorporate historical changes in social variables that influence 
vulnerability, such as in the fields of food security and land degradation (Watts 1983, Fraser 2003) and climate change and climate variability (Endfield 2007).

The differences and complementarities in temporal scales considered in resilience and vulnerability research can be understood in terms of the metaphor of 'bifocal' lenses. A bifocal approach that integrates both resilience and vulnerability enables a focus on longer term biophysical system drivers as well as nuanced, contemporary local socioeconomic realities. This can be built on to enable development responses that integrate local priorities with an holistic understanding of the biophysical system.

Ongoing work in Ceará, Brazil addresses current vulnerabilities to climate variation while also developing the features that characterize a more resilient system. The introduction of a local planning system prioritizes actions that reduce exposure to drought and enhance the ability to cope. This process contributes to a transformation of the governance system, reorienting resource and information flows, and thus developing a foundation that encourages learning, diversity, and flexibility in response to ongoing change (Nelson and Finan 2009).

\section{Different yet complementary spatial scales of analysis}

Because of the interplay of multiple processes of social and environmental change, which manifest themselves at different spatial scales, each field seeks to adopt a multiscale perspective. However, the spatial scales of analysis often differ between the resilience and vulnerability communities. Resilience research has tended to consider the ecologically bounded scales of the ecosystem, landscape, and region (Cumming et al. 2006). Vulnerability research, in contrast, tends to consider socially defined scales of the household, community, region, and nation, although the basin and landscape are also considered.

Both fields are characterized by either very localized case studies based on empirical research, or global analyses based on highly aggregated data. There is a joint recognition that more multiscale case studies are needed, which capture the interaction between dynamic processes, the impediments to resilience, and the manifestation of vulnerability that occur at different scales. A recent integrated study by Eakin and Webbe (2009) demonstrates such a multiscale analysis of the interactions and feedbacks between local vulnerability and wider system sustainability.

A related aspect is the frequent distinction made in vulnerability research between "top-down" and "bottom-up" methodologies (Dessai and Hulme 2004). The top-down methodologies largely originate from climate impact assessment, focus on the biophysical aspects of vulnerability, and apply climate scenarios and impact models. The bottomup methodologies originate from the fields of poverty reduction, livelihood studies, disaster risk reduction, development, and food security, e.g., participatory rural appraisal; they are usually case study based and often focus on social conditions, institutions, and the perception of vulnerability. The choice of whether top-down or bottom-up methodologies are chosen greatly depends on the particular research questions and objectives, and the extent to which stakeholders' perspectives are considered critical. Partly because of the local case study focus of many vulnerability assessments, the findings of such studies can be highly context and place-specific, features critical to addressing local policy concerns. It is clear that to generate more general insights from the rich and diverse case study analyses in both resilience and vulnerability research, there is a need for greater meta-analysis as a first step to further theoretical innovation. A key issue is to link different assessments at different scales by up- and down-scaling as well as to identify clearly which type of vulnerability characteristics and dynamics can solely be captured through local approaches and which type of features and dynamics can be captured by approaches at mesoand macroscales.

\section{Social and ecological dynamics and feedbacks}

A better understanding of the interactions and relations within SES requires the identification of social-ecological feedbacks. This is very challenging because of disconnects between our actions and system feedbacks. Feedback mechanisms can be masked through economic distortions and subsidies, and they may also be deferred in time and space. Processes in one region can have resounding effects in distant areas (Berkes et al. 2006, Adger et al. 2009). 
Feedbacks determine system states and regime shifts, and occur at different scales. Selection of appropriate scales of analysis therefore determines the extent to which feedbacks within a system can be captured. Feedbacks between social and ecological processes are important, yet it is also important to recognize that the social and ecological components of such systems may be operating at different scales and be on different pathways (Galaz et al. 2008). There can thus be tensions between social resilience and ecological resilience, as social resilience may be realized at one scale, say the local community, yet through extended feedbacks such as the effect of agricultural activities on downstream water quality, ecological resilience may be undermined at another scale such as the catchment. For example, empirical evidence from case studies of poverty, agricultural change, and land management in South Africa suggest that it may not be obvious where different ecosystem services are working in synergy rather than in conflict because of the complexity of the development process (Fabricius et al. 2004). It is critical to understand these feedbacks among multiple stressors, particularly when seeking to assess their contribution to stability and change in systems, and evaluate the implications of these processes (Osbahr et al. 2007). The development of assessment methods to fully appreciate and capture these feedbacks and tensions is required. Although vulnerability assessment has significantly developed in recent years, expanding from a dominant focus on the hazard or triggering event to consider the wider social and environmental context in which hazards are transformed into disasters and in which disaster risk and adaptation options are determined, it still faces major challenges in terms of capturing social and ecological feedbacks.

Concomitant to a better understanding of feedbacks in SES is the identification of the role of thresholds, and how these relate to shifts toward different system states, which may be considered desirable or undesirable. In resilience theory thresholds are defined as boundaries between alternate system states, or stability domains (see explanation of terms in Walker et al. 2004), and crossing a threshold involves a change in the nature and extent of feedbacks associated with a key variable, e.g., water quality. However, it is obvious that defining thresholds such as 'dangerous' climate change, is not just a question of science but involves a value judgment (Eakin and Luers 2006). Thus, research is needed that improves our understanding of both social and ecological thresholds and the interlinkages between them.

There is much interest in using indicators as measures of resilience and vulnerability (Hinkel 2010). As vulnerability and resilience involve many attributes and multiple stresses, which change at different speeds, they are dynamic (O'Brien and Leichenko 2001). As such, we cannot assume to be able to capture a vulnerability or resilience state per se using static indicators that represent an outcome, e.g., income or GDP per capita, rather than a dynamic process, e.g., proportion of labor force employed (Downing et al. 2005). For instance, although vulnerability assessments aim to capture longer term dynamics, in practice they often present a snapshot of vulnerability at a particular time, such as immediately after a disaster. This can thus obscure the processes that influence and constrain avoidance, preparation, coping, resistance, and recovery decision making and activities over longer time frames. Dynamic indicators that capture the functional processes of the system and the interrelationships between them are needed to identify changes in vulnerability or resilience over time, because such insights may assist in identifying appropriate opportunities for intervention. Furthermore, the vulnerability of people to natural hazards and climate change is also influenced and reconfigured by the interventions in postdisaster processes and adaptation measures proposed (Birkmann et al. 2008, Birkmann and Fernando 2008).

In attempting to integrate the dynamic aspects of vulnerability into water catchment planning, Downing et al. (2005) noted six attributes that are important to explore when identifying the degree to which a particular development pathway is likely to lead to sustainability and/or resilience. These attributes and possible methods to explore them are:

1. Vulnerability is the differential exposure to stresses experienced or anticipated by different units; this can be measured using methods such as a livelihoods-sensitivity matrix.

2. Vulnerability is not static but rather is constantly changing; the degree and nature of this change can be visualized in different scenarios in an agent-based model.

3. Vulnerability is rooted in the actions and multiple attributes of human actors; eliciting 
knowledge to create heuristics and rules of decision making, which includes the tacit knowledge that often drives such decisions, can be explored, e.g., Bharwani (2006).

4. Vulnerability is driven and bounded by social networks; again this can be explored using a variety of approaches from participatory methods such as focus group discussions and interviews, e.g., using NetMap (http://netmap. ifpriblog.org), to more formal social networks analysis.

5. Vulnerability is constructed simultaneously on more than one scale; slow and rapid change at different scales can be observed in an agentbased model (Bharwani et al. 2005) context, while using decision making knowledge derived at any level, e.g., an individual, household, or institution etc.

6. Multiple stresses are inherent in integrating the vulnerability of peoples, places, and systems; multiple perspectives and differing perceptions of risk should be explored, using bottom-up participatory approaches, as communities are always responding to a complex combination of stressors (e.g., Ziervogel et al. 2006a).

A great challenge lies in applying these issues as standards in vulnerability analyses where vulnerability is often assumed to be static and not affected by feedbacks both in the SES and by human agency. Thus, in seeking to understand the vulnerability of local communities in Lesotho within the wider frame of dynamic vulnerability, Bharwani et al. (2007) conducted an analysis of local users of ecosystems services with respect to institutional bridges and barriers relating to the preservation of wetland areas. In this study, the dynamic attributes of vulnerability were explored using some of the methods mentioned above, which applied a more holistic lens to the complex feedbacks inherent in such systems and the potential pathways to resilience and sustainability or to decline and degradation. The case of Highland communities' use of ecosystem services illustrates many aspects of SES research, such as slow and rapid change at different scales and in different sectors. It also highlights decision making carried out in response to a range of stressors, such as climate, health, and economics against a backdrop of cultural preferences and socio-cultural change.
The framework and methods described above are helpful in capturing a range of SES feedbacks and identifying the relationships and interactions between different parts of the system, making it possible to identify where new or unexpected vulnerabilities may emerge, e.g., impacts at different scales, and thus possible areas for intervention.

Though the concept of SES (Berkes and Folke 1998) is now commonly used in resilience and vulnerability research to stress integration and linkages between social and ecological components of systems, the above discussion shows that the methodological issues around doing truly integrated SES research are still dealt with in fairly immature ways. The complexity of these issues is reflected in the increasingly hybrid and pluralistic approach to methodologies. Divergences and convergences are apparent between the different research communities, specifically in how they address issues of temporal scale, spatial scale, and capturing dynamics and feedbacks. Greater collaboration between researchers could assist in advancing truly integrated approaches to inquiry into social-ecological change, and help in developing appropriately scaled case studies that go beyond the current polarized situation of local or global studies. The examples of ABM and hybrid approaches given above demonstrate positive moves toward truly integrated inquiry.

\section{KEY INSIGHTS CONCERNING THE APPLICATION OF RESILIENCE - VULNERABILITY PERSPECTIVES}

Although greater mutual understanding between the resilience and vulnerability academic research communities is occurring, there is still a big gap between the academic and the policy and practitioner communities with respect to the application of the concepts of resilience and vulnerability (Osbahr et al. 2007, Vogel et al. 2007, Boyd et al. 2008). A workshop that brought together academics and development practitioners working in Africa (Osbahr et al. 2007) demonstrated this beyond any doubt. However, although vulnerability concepts and assessments have long been incorporated into practice in the development, food security, and disaster risk communities, there are few examples that document how resilience is explicitly incorporated into practice and policy. Although there is a growing body of research 
developing our understanding of resilience, there are few documented cases of how this understanding is adopted and applied by practitioners, managers, community leaders, and policy makers, notable exceptions being the work undertaken on Kristianstads Vattenrike in southern Sweden (Olsson et al. 2004), and the case studies brought together by Gunderson and Holling (2002), Berkes et al. (2003), and Walker and Salt (2006). As such, it is an outstanding challenge to document resilience in practice.

To better engage the development policy community in thinking about pressing ecological or climate issues, we therefore need to translate the concepts related to resilience and vulnerability thinking in constructive ways that help to solve practical development challenges. Recent advances have been made through efforts of the Resilience Alliance to better communicate key research concepts (Walker and Salt 2006) and operationalize resilience assessment methods via an evolving "workbook", now in a 'wiki' format (see http://wik i.resalliance.org). Similar initiatives have also been taken in vulnerability and climate change research (see http://www.wikiadapt.org).

Kasperson et al. (2005:162) argue that, though there are limitations in theory, data, and methods, "sufficient knowledge exists in most regions to apply vulnerability analysis to contemporary problems of ecosystem management and sustainable development in order to provide useful information to decision-makers and practitioners." However, both resilience and vulnerability research would have much greater effect if they could better identify specific intervention points and possible pathways to vulnerability reduction, and come up with an assessment of the benefits and losses that would result from a failure to intervene. Clearly describing such negative outcomes would provide a strong incentive to policymakers and practitioners to push for the appropriate changes in policy, governance, and action. This remains a major outstanding challenge.

\section{Policy and practitioner engagement}

Because of its stress on positive and transformative processes, resilience as a concept has significant colloquial and policy appeal, whereas a vulnerability focus can be construed as negative and potentially stigmatizing, particularly if research is undertaken by outsiders with little community or stakeholder input or influence. The labeling of certain groups or regions as vulnerable can also result in potentially regressive policy decisions and justifications for intervention that undermine community autonomy or increase marginalization. However, resilience needs to be managed, because it is not always appropriate and not in the interest of all stakeholders. Hence, the emergence of a growing emphasis on transformation (Walker et al. 2004).

Traditionally resilience and vulnerability research have focused on different policy domains and challenges. Resilience research has tended to focus on ecosystems, both terrestrial and marine, and on natural resource management in key sectors, such as fisheries, agriculture, rangelands, and forestry. Vulnerability research has long had experience in linking research with policy and practice in key areas such as disaster risk reduction, livelihoods, food insecurity, and climate change adaptation. This has been facilitated by the translation of work into various assessment methodologies, manuals, and tools (Stephen and Downing 2001, Downing and Patwardhan 2002, Füssel and Klein 2006, Famine Early Warning Systems Network 2008; http://www. fews.net), and their partial adoption by agencies, such as the World Bank in their Poverty Reduction Strategy Papers (Miller et al. 2008a) and United Nations Development Programme. For example, the International Federation of the Red Cross and Red Crescent Societies (IFRC), the world's largest independent humanitarian agency, has long applied vulnerability and capacity assessments in their work (IFRC 1996, 1999, 2006a, 2006b, 2006c, 2006d, IFRC and Caribbean Red Cross Societies 2003). Researchers from the Stockholm Environment Institute recently partnered with the Red Cross movement in post-tsunami Sri Lanka to undertake such assessments. Such links between researchers and humanitarian workers, and the application of vulnerability assessments can be further improved and strengthened, particularly in terms of the timeliness of such assessments in relation to the humanitarian agencies' requirements and ways in which assessments can minimize the burden on disaster-affected communities.

The long experience in applying vulnerability assessment has allowed the refinement of our understanding of how and why certain groups are more severely affected by change than others, and selection of appropriate methods to assess this, but 
an outstanding challenge remains how to better access the perspectives of the most vulnerable and to incorporate issues of social-ecological resilience. One of the major weak points of vulnerability assessments is the incorporation of the environmental implications of coping and adaptation strategies. Traditional social science approaches often tend to solely focus on the responses within social systems, while for example livelihood strategies imply major changes in environmental conditions that in turn may influence future vulnerabilities (Birkmann 2006). More recent interpretations of vulnerability incorporate resilience aspects particularly in terms of social, institutional, and organizational learning, yet these factors are difficult to assess and examine before actual shocks and events occur. Toward this aim, however, agencies such as the Asian Disaster Preparedness Centre (ADPC) and Tearfund (Twigg 2007) have developed guidelines on how to build resilience to coastal hazards in communities.

Though resilience and vulnerability researchers are indeed engaging with policy and practitioner communities and sectors, any convergence of the two approaches at conceptual and methodological levels should be extended to the policy and practitioner interface. One area where a degree of crossover is already occurring is the field of disaster risk reduction, a field in which vulnerability research has long been of interest (Burton et al. 1978, Hewitt 1983). An example of how resilience is interpreted by practitioners of disaster risk reduction is the ADPC, where resilience is conceived as incorporating the following key dimensions: (1) the ability to absorb shocks, (2) the ability to bounce back, and (3) the ability to learn and adapt (Ahmed 2006). It is suggested that resilience can be influenced by interventions aimed at reduction of risk, decreasing recovery time, and learning from experience. Another example is the Department for International Development guidance note on the Characteristics of a Disaster-Resilient Community (Twigg 2007).

However, although disaster risk reduction practitioners are increasingly using the term resilience (Buckle 2000, IFRC 2004, UN ISDR 2005, Ahmed 2006; H. Osbahr and E. Boyd, unpublished manuscript; see www.proventioncons ortium.org), there is often a disconnect between the application of this concept in that community and the conceptual work that underpins the term in the academic resilience community. For instance, there is much research on the importance of various factors in building general resilience (see Berkes and Seixas 2005), yet this information is often only marginally used among practitioners in policy domains, because there is little detailed guidance on how building resilience might actually be undertaken, i.e., guidance on identifying which actors should be involved, at what scale, which resources are required, which management options exist, and so on.

Resilience thinking recognizes the danger in producing detailed manuals and blueprints when governing complex SES (Ostrom 2007), but nevertheless guidance needs to be improved on the process of enhancing the resilience of desired SES and removing it from undesired ones. For example, although the United Nations' International Strategy for Disaster Reduction (UN ISDR) Hyogo Framework (2005) gives explicit consideration to issues of resilience, in particular the role of adaptation, learning, and risk reduction, it does not substantially elaborate on how resilience thinking, in particular managing uncertainty and surprise, necessitates a very different approach than previous disaster reduction planning and action. There are also significant cultural, institutional, and political barriers that need to be overcome in managing for resilience. The complexity of the concept of SES resilience and the multidisciplinary nature of resilience assessment form significant institutional barriers to the application of resilience thinking by policy makers, as suggested by Lemos et al. (2007) and Boyd et al. (2008). There is thus a strong need for examples in different contexts, building on the study of transformation by Olsson et al. (2006), which illustrates how to address such implementation challenges.

There are obvious benefits associated with adopting an integrated approach by resilience and vulnerability researchers to their engagement with policy actors and practitioners. One such benefit is to take advantage of the relative success of practically applying vulnerability assessment to a more refined understanding of socially differentiated responses to social-ecological change, and another is that it enables us to improve our understanding of the environmental implications of coping and adaptation activities. 


\section{Bridging research-policy-practitioner divides: toward social learning}

There is a growing recognition of the need to shift from output-directed to process-oriented research that sees knowledge as coproduced by a plurality of actors, including scientists, researchers, and policy and community stakeholders (Gibbons 1999, Jasanoff 2003, Lemos and Morehouse 2005, Dabelko 2006, Vogel et al. 2007). Vogel et al. (2007:349) call for an alternative approach to the usual one-way interaction between scientists and practitioners, in which, "different experts, riskbearers, and local communities are involved and knowledge and practice is contested, co-produced and reflected upon." They acknowledge that although there has been a growing effort toward increasing partnership-based approaches, major challenges remain, notably in terms of developing a consensus on methodology, timely delivery of research results, the need for time consuming, negotiated understanding between science and practice, and clarity on the role of 'external' stakeholders (Vogel et al. 2007). The timeliness of research is a particular challenge for those involved in research on critical ecological thresholds and disaster recovery, because of the limited windows of opportunity that exist for research to inform appropriate policy and actions.

Another common challenge associated with the communication and translation of research in both fields is that many recommendations from case studies are often either highly specific for a locality, or too general and normative, focusing only on what should be done without necessarily considering what can be done and how. There is little guidance on how to actually do this within the constraints and opportunities that exist in various contexts. For example, to gain better understanding of rapid organizational responses to climate change or biodiversity loss, exploratory research collaborations are called for that engage with organizations and processes across scales of decision making. These organizations include the UN, government departments, private businesses, and NGOs, which are perhaps not accustomed to 'letting in' researchers to examine the details of what capacity needs exists, how information flows, how science is interpreted, and what the politics are of internal capacity building (Boyd and Osbahr 2010). The aim here is not to develop blueprints for practitioners, as such, but rather help guide their exploration of complex SES. Research exploring institutional learning, dealing with uncertainty and complex risks, and the communication or delivery in practice would be timely (Boyd and Osbahr 2010; H. Osbahr and E. Boyd, unpublished manuscript).

There are limits, however, to the kinds of decisions with which researchers should be involved. In the case of vulnerability indicators, some decisions about weighting and limits are more political than academic, or have a tendency to become political so that academic rigor is lost (Hinkel 2010). The case of identifying 'the particularly vulnerable' in the context of the United Nations Framework Convention on Climate Change is an example of the often blurred boundaries between academic and political questions (Klein 2008, as cited in Miller et al. 2008b).

There is a need to reframe issues in terms of social learning, and the capacity of coupled systems to learn in order to be relevant for critical policy processes such as climate change (Lemos et al. 2007, Boyd et al 2008, Krasny et al. 2010). This is because of a common recognition that any resilience or vulnerability assessment needs to consider the views, knowledge, and experience of different stakeholders at different scales to facilitate a process of joint learning and reflection that will lead to the joint development of acceptable solutions (Vogel et al. 2007, see also Thomalla et al. 2009). Often, assessments are undertaken for or by a particular stakeholder, such as a government agency or humanitarian organization, and few opportunities exist to share lessons and engage in joint learning among different actors (Larsen et al. 2009, Thomalla et al. 2009) so as to improve the capacity to live with change. The increasing effects of natural disasters and the politics of postdisaster aid demonstrate our limited ability to take stock and to adjust our practices. Thus, we are slow in learning important lessons about improving collective action, and developing approaches that balance short term humanitarian relief with medium and long term sustainability considerations. We are also slow in promoting adaptation to future environmental changes and hazards, e.g., climate change, and in improving the targeting and self-help capacities of those affected. (Thomalla et al. 2009).

Institutional set-ups usually do not allow for social learning that crosses institutional levels and timeframes (Keen et al. 2005). Positive changes can be achieved if space for such reflection and learning is created (Pahl-Wostl et al. 2008). Resilience 
research can help to design opportunities for reflection and learning, and appropriate networks, institutions, and governance structures (Folke et al. 2003, Pahl-Wostl et al. 2007). There is a need to consider the complexities of how relations among multiple institutional levels play out in governance, and in particular how knowledge, perspectives, and experience can be shared or constrained. Instead of just dealing with the roles of actors in the process, there is a need to also consider how they absorb shocks and reorganize. Specifically in relation to ecological systems, there are several concrete examples of institutional learning, managing complexity, and the value of resilience building. Research in Mozambique, for example, has illustrated how important the scale dimensions of institutional practice and self-organization, such as relations among different levels of institutions, become when one is developing response strategies that manage both sudden and slower climate change and, in particular, when integrating plans for food security, poverty reduction, and building resilience in smallholder farming communities (Osbahr et al. 2008). The research highlighted the importance of forums for sharing experiences and practical innovation, in this case for agricultural resilience to flooding and drought. There are other examples of multiple stakeholders sharing knowledge, managing complexity, and building adaptive capacity that have led to improved management of fragile ecosystems affected by climate change and increasing variability across Africa (Thomas et al. 2007).

\section{CONCLUSIONS AND WAYS FORWARD}

We are confronted with enormous global challenges, including chronic poverty and inter- and intra-national economic and social inequalities, persistent food insecurities, as well as major challenges associated with urbanization, land and water degradation, biodiversity, habitat loss and fragmentation, natural disasters, and climate change. Concurrently, there are also many positive changes and innovative approaches to such challenges in governance, as well as in the community and private sectors. Resilience research in particular, through the study of transformation and learning, is able to emphasize such positive actions and to point the way to how they might be replicated or upscaled. Concomitantly, vulnerability research, through its focus on power and the limitations of individual agency, is able to identify political dimensions that prevent progressive socialecological changes from occurring. However cogent, relevant, and appropriate research in resilience and vulnerability may seem to be in addressing major social-ecological challenges, there is a need to be constantly self-reflexive and critical of the concepts and tools we apply.

We have identified key areas of convergence where resilience and vulnerability research can contribute on a common front, strengthening the ability to solve real world problems. A number of future directions can assist in the integration of resilience and vulnerability approaches to better address questions of social-ecological change.

\section{In terms of theory,}

- Resilience and vulnerability, as they differentially emphasize ecological-biophysical or social-political dimensions of problems under investigation, offer real opportunities for integration, particularly as they are both oriented toward responses to stress and perturbations, and the interaction of slow and rapid changes.

- Opportunities exist to draw upon the respective strengths of systems thinking in understanding dynamic social-ecological relations, and actor-oriented approaches in understanding matters of social differentiation, equity, and power.

- Both resilience and vulnerability researchers need to move beyond interpreting the other field through their own language and work toward a common lexicon that allows mutual understanding.

- To address questions of transformation and adaptation, there is a real need to draw upon the experience of the vulnerability community in the subjective domain of values, power, and social differentiation. However, at the same time, addressing the environmental consequences of different recovery and adaptation options remains a challenge within studies of vulnerability. 
In terms of methodology,

- Resilience and vulnerability researchers need to work together on common case studies, at multiple spatial scales, in a way that seeks to resolve the current polarized approach to either local or global case studies. Longitudinal studies of resilience and vulnerability over time are another key area of concern.

- The move toward more hybrid and pluralistic approaches in research methodology, such as the incorporation of participatory research with agent based modeling, demonstrates positive changes in the domain of integrated social-ecological inquiry. Incorporation of such diverse methods is critical to capturing diverse perspectives on system dynamics. There is a need to further develop and apply approaches that focus more strongly on the needs of those affected by disasters and stresses, because those most affected are rarely part of studies, or if they are, the extent to which their voices are heard is limited.

In terms of application,

- There is an urgent need to translate complex conceptual insights into operational assessment methodologies, guidelines, and procedures that are easily accessible to practitioners and decision makers. One step toward this could consist of the development of integrated vulnerability and resilience assessments that guide people to select from concepts and tools in the respective areas of resilience and vulnerability to match the issues at hand.

- Collaboration of resilience and vulnerability researchers with policy actors and practitioners would allow for the strength of each approach to be built upon, to ensure integrated approaches that address both the socially differentiated nature of responses to socialecological change, and the environmental implications of investment in different coping and adaptation activities.

- We need to create mechanisms for collective reflection and learning among researchers, policymakers, and practitioners and among different stakeholders, so as to better capture important lessons learned.

Exploration of the interlinkages and the possibilities for integration between resilience and vulnerability research is still at an early stage, and there remains some confusion in language and concepts that inhibits such integration and hampers collaborative research. What is clear from this paper, though, is that resilience has advanced our understanding of system dynamics and interconnections, ecological thresholds, social-ecological relations, and feedbacks. An understanding of ecological and biophysical processes is of course essential for anticipating, adapting to, and managing change. A more sophisticated understanding of social and political processes, and in particular the distribution of costs, risks, and benefits created by environmental change, is also required, and this is where vulnerability research makes important contributions. There are promising directions emerging from the application of hybrid and pluralistic approaches to inquiry into social-ecological change, as well as advances being made in engagement between academic and policy and practitioner communities. Although tensions and obvious differences will no doubt persist, this study has shown that resilience and vulnerability approaches together can advance a more integrated understanding of social-ecological change.

Responses to this article can be read online at: http://www.ecologyandsociety.org/voll5/iss3/art11/ responses/

\section{Acknowledgments:}

This paper emerged and benefited from the contributions and discussions of participants of a workshop held in Stockholm in April 2008 organized by the Stockholm Environment Institute and Stockholm Resilience Centre in cooperation with the University of Melbourne. The Resilience Vulnerability Colloquium, From Theory to Practice, From Disconnect to Synergy in Support of Sustainable Development was made possible through financial support from the Stockholm Resilience Centre, Formas, the Vetenskapsrådet, and internal SEI funds. We wish to acknowledge the valuable contributions of the participants of this 
workshop to the ideas that have been further explored in this paper.

\section{LITERATURE CITED}

Adger, N. W. 1999. Social vulnerability to climate change and extremes in coastal Vietnam. World Development 27:249-269.

Adger, N. W. 2000. Social and ecological resilience: are they related? Progress in Human Geography 24 (3):347-364.

Adger, N. W. 2006. Vulnerability. Global Environmental Change 16:268-281.

Adger, W. N., H. Eakin, and A. Winklels. 2009. Nested and teleconnected vulnerabilities to environmental change. Frontiers in Ecology and the Environment 7(3):150-157. doi: 10.1890/070148.

Ahmed, A. K. 2006. Concepts and practices of 'resilience': a compilation from various secondary sources. A Working paper prepared for Coastal Community Resilience (CCR) Program, U.S. Indian Ocean Tsunami Warning Systems (IOTWS) Program, Bangkok, Thailand.

Archer, E. R. M., N. M. Oettlé, R. Louw, and M. A. Tadross. 2008. Farming on the edge in arid western South Africa: climate change and agriculture in marginal environments. Geography 93 (2):98-107.

Alwang, J., P. B. Siegel, and S. L. Jorgensen. 2000. Vulnerability: a view from different disciplines. World Bank, Washington, D.C., USA.

Barnett, J. 2001. Adapting to climate change in Pacific island countries: the problem of uncertainty. World Development 29:977-993.

Barnett, J. 2003. Security and climate change. Global Environmental Change 13:7-17.

Berkes, F., J. Colding, and C. Folke, editors. 2003. Navigating the dynamics of social-ecological systems: building resilience for complexity and change. Cambridge University Press, Cambridge, UK.
Berkes, F., and C. Folke. 1998. Linking social and ecological systems: management practices and social mechanisms for building resilience. Cambridge University Press, Cambridge, UK.

Berkes, F., T. P. Hughes, R. S. Steneck, J. A. Wilson, D. R. Bellwood, B. Crona, C. Folke, L. H. Gunderson, H. M. Leslie, J. Norberg, M. Nyström, P. Olsson, H. Österblom, M. Scheffer, and B. Worm. 2006. Globalization, roving bandits, and marine resources. Science 311:1557-1558.

Berkes, F., and C. S. Seixas. 2005. Building resilience in lagoon social-ecological systems: a local-level perspective. Ecosystems 8:967-94.

Bharwani, S. 2006. Understanding complex behavior and decision making using ethnographic Knowledge Elicitation Tools (KnETs). Social Science Computer Review 24(1):78-105.

Bharwani, S., M. Bithell, T. E. Downing, M. New, R. Washington, and G. Ziervogel. 2005. Multiagent modelling of climate outlooks and food security on a community garden scheme in Limpopo, South Africa. Philosophical Transactions of the Royal Society B-Biological Sciences $\mathbf{3 6 0}$ (1463): 2183-2194.

Bharwani, S., M. Shale, A. Taylor, N. Matin, and T. E. Downing. 2007. Integrating social vulnerability into water management in the Lesotho Highlands: the case of Ha Tsiu. Proceedings of the International Conference on Adaptive \& Integrated Water Management - Coping with complexity and uncertainty (CAIWA). 12-16th November, Basel, Switzerland. Electronic version (CD compilation). [online] URL: http://www.newater.uos.de/caiwa/data/ papers\%20session/D3/Vul Resil Lesotho final.pdf

Biggs, H., S. Pollard, and D. du Toit. 2007. Systematic links between society, wetlands and woodlands -the Bushbuckridge case. Natural Forests and Savanna Woodlands Symposium IV Proceedings. May 2007, Port Elizabeth, South Africa.

Birkmann, J. 2006. Measuring vulnerability to natural hazards - towards disaster resilient societies. UNU-Press, Tokyo, Japan.

Birkmann, J., P. Buckle, J. Jaeger, M. Pelling, N. Setiadi, M. Garschagen, N. Fernando, and J. 
Kropp. 2008. Extreme events and disasters: a window of opportunity for change? Analysis of organizational, institutional and political changes, formal and informal responses after mega-disasters. Natural Hazards DOI 10.1007/s11069-008-9319-2

Birkmann, J., and N. Fernando. 2008. Measuring revealed and emergent vulnerabilities of coastal communities to tsunami in Sri Lanka. Disasters 32 (1):82-104.

Blaikie, P., T. Cannon, I. Davis, and B. Wisner. 1994. At risk: natural hazards, people's vulnerability and disasters. Routledge, London, UK.

Bohle, H. G., T. E. Downing, and M. Watts. 1994. Climate change and social vulnerability: the sociology and geography of food insecurity. Global Environmental Change 4(1):37-48.

Boyd, E., and H. Osbahr. 2010. Resilient response to climate change: Exploring organisational learning in networked development organisations. Environmental Education Research, in press.

Boyd, E., H. Osbahr, P. J. Ericksen, E. L. Tompkins, M. C. Lemos, and F. Miller. 2008. Resilience and "climatizing" development: examples and policy implications. Development 51:390-396.

Buckle, P. 2000. Guidelines for assessing resilience and vulnerability in the context of emergencies. Victorian Government, Department of Human Services, Melbourne, Australia.

Burton, I., R. W. Kates, and G. F. White. 1978. The environment as hazard. Oxford University Press, Oxford, UK.

Cannon, T. 2008. Reducing people's vulnerability to natural hazards communities and resilience. United Nations University - World Institute for Development Economics Research, Bonn, Germany.

Carpenter, S. R., N. F. Caraco, D. L. Correll, R. W. Howarth, A. N. Sharpley, and V. H. Smith. 1998. Non-point pollution of surface waters with phosphorus and nitrogen. Ecological Applications 8:559-568.

Carpenter, S., B. Walker, J. M. Anderies, and N. Abel. 2001. From metaphor to measurement: resilience of what to what? Ecosystems 4:765-781.
Chambers, R. 1989. Editorial introduction: vulnerability, coping and policy. Institute of Development Studies Bulletin 20(2):1-7.

Chambers, R., and G. R. Conway. 1992. Sustainable rural livelihoods: practical concepts for the 21st century. IDS Discussion Paper 296. Institute of Development Studies, University of Sussex, Brighton, UK.

Chapin, F. S., III, S. R. Carpenter, G. P. Kofinas, C. Folke, N. Abel, W. C. Clark, D. Olsson, M. S. Smith, B. Walker, O. R. Young, F. Berkes, R. Biggs, M. Grove, R. L. Naylor, E. Pinkerton, W. Steffen, and F. J. Swanson. 2009. Ecosystem stewardship: sustainability strategies for a rapidly changing planet. Trends in Ecology and Evolution 25(4):241-249. doi:10.1016/j.tree.2009.10.008

Cumming, G. S., D. H. M. Cumming, and C. L. Redman. 2006. Scale mismatches in socialecological systems: causes, consequences, and solutions. Ecology and Society 11(1): 14. [online] URL: http://www.ecologyandsociety.org/vol11/iss 1/ $\underline{\operatorname{art14/}}$.

Dabelko, G. 2006. Turning up the volume on the science-practice interface in global change. IHDP Update, Newsletter of the International Human Dimensions Programme on Global Environmental Change 3(4):1-5.

Dessai, S., and M. Hulme. 2004. Does climate adaptation policy need probabilities? Climate Policy 4(2): 107-128.

Downing, T. E., J. Aerts, J. Soussan, O. Barthelemy, S. Bharwani, C. Ionescu, J. Hinkel, R. J. T. Klein, L. J. Mata, N. Martin, S. Moss, D. Purkey, and G. Ziervogel. 2005. Integrating social vulnerability into water management. SEI Working Paper and Newater Working Paper No. 4. Stockholm Environment Institute, Oxford, UK.

Downing, T. E., R. Butterfield, S. Cohen, S. Huq, R. Moss, A. Rahman, Y. Sokona, and L. Stephen. 2001. Climate change vulnerability: linking impacts and adaptation. The Governing Council of the United Nations Environment Programme (UNEP), University of Oxford, Oxford, UK.

Downing, T. E., and A. Patwardhan. 2002. Vulnerability assessment for climate adaptation. 
Adaptation Planning Framework Technical Paper, Oxford, UK.

Eakin, H., and A. L. Luers. 2006. Assessing the vulnerability of social-environmental systems. Annual Review of Environment and Resources 31:365-94.

Eakin, H., and M. Webbe. 2009. Linking local vulnerability to system sustainability in a resilience framework: two cases from Latin America. Climatic Change 93:355-377.

Ellis, F. 2000. Rural livelihoods and diversity in developing countries. Oxford University Press, Oxford, UK.

Endfield, G. 2007. Archival explorations of climate variability and social vulnerability in colonial Mexico. Climatic Change 83:9-38.

Fabricius, C., E. Koch, H. Magome, and S. Turner. 2004. Rights, resources and rural development: community based natural resource management in Southern Africa. EarthScan, London, UK.

Folke, C. 2006. Resilience: the emergence of a perspective for social-ecological systems analyses. Global Environmental Change 16:253-267.

Folke, C., S. Carpenter, T. Elmqvist, L. Gunderson, C. Holling, B. Walker, J. Bengtsson, F. Berkes, J. Colding, K. Danell, M. Falkenmark, L. Gordon, R. E. Kasperson, N. Kautsky, A. Kinzig, S. Levin, K. G. Maler, F. Moberg, L. Ohlsson, P. Olsson, E. Ostrom, W. Reid, J. Rockstrom, H. Savenije, and U. Svedin. 2002. Resilience and sustainable development: building adaptive capacity in a world of transformations. Scientific Background Paper on Resilience for the process of the World Summit on Sustainable Development. Environmental Advisory Council to the Swedish Government, Stockholm, Sweden.

Folke, C., J. Colding, and F. Berkes. 2003. Synthesis: building resilience and adaptive capacity in social-ecological systems. Pages 352-387 in F. Berkes, J. Colding, and C. Folke, editors. Navigating social-ecological systems: building resilience for complexity and change. Cambridge University Press, Cambridge, UK.
Folke, C., T. Hahn, P. Olsson, and J. Norberg. 2005. Adaptive governance of social-ecological systems. Annual Review of Environment and Resources 30:441-73.

Fraser, E. D. G. 2003. Social vulnerability and ecological fragility: building bridges between social and natural sciences using the Irish Potato Famine as a case study. Conservation Ecology 7(2):9. [online] URL: http://www.consecol.org/vol7/iss2/art9/

Füssel, H. M., and R. Klein. 2006. Climate change vulnerability assessments: an evolution of conceptual thinking. Climatic Change $\mathbf{7 5}$ (3):301-329.

Galaz, V., T. Hahn, P. Olsson, C. Folke, and U. Svedin. 2008. The problem of fit among biophysical systems, environmental regimes and broader governance systems: insights and emerging challenges. Pages 147-186 in O. R. Young, H. Schroeder, and L. A. King, editors. Institutions and environmental change: principal findings, applications, and research frontiers. MIT Press, Cambridge, Massachusetts, USA.

Gallopín, G. C. 2006. Linkages between vulnerability, resilience, and adaptive capacity. Global Environmental Change 16(3):293-303.

Gibbons, M. 1999. Science's new social contract with society. Nature 402:C81-C84.

Gunderson, L. H., and C. S. Holling, editors. 2002. Panarchy: understanding transformations in human and natural systems. Island Press, Washington, D.C., USA.

Hewitt, K. 1983. Interpretations of calamity: from the viewpoint of human ecology. Allen and Unwin, Boston, Massachusetts, USA.

Hinkel, J. 2008. A framework for the analysis of integrated methodologies of vulnerability assessments. In A. G. Patt, D. Schröter, A. C. de la Vega-Leinert, and R. J. T. Klein, editors. Environmental Vulnerability Assessment. Earthscan, London, UK.

Hinkel, J. 2010. Measuring vulnerability and adaptive capacity: towards a clarification of the science policy interface. Global Environmental Change, in press. 
Holling, C. S. 1996. Engineering resilience versus ecological resilience. Pages 31-44 in P. C. Schulze, editor. Engineering within ecological constraints. National Academic Press, Washington, D.C., USA.

Holling, C.S., and G. Meffe. 1996. Command-andcontrol and the pathology of natural resource management. Conservation Biology 10:328-337.

International Federation of Red Cross and Red Crescent Societies (IFRC). 1996. Vulnerability and capacity assessment toolbox. IFRC, Geneva, Switzerland.

International Federation of Red Cross and Red Crescent Societies (IFRC). 1999. Vulnerability and capacity assessment: an international federation guide. IFRC, Geneva, Switzerland.

International Federation of Red Cross and Red Crescent Societies (IFRC). 2004. World disasters report 2001: focus on community resilience. IFRC, Geneva, Switzerland.

International Federation of Red Cross and Red Crescent Societies (IFRC). 2006a. What is VCA? A guide to vulnerability and capacity assessment. IFRC, Geneva, Switzerland.

International Federation of Red Cross and Red Crescent Societies (IFRC). 2006b. How to do a VCA: A practical step-by-step guide for Red Cross Red Crescent staff and volunteers. IFRC, Geneva, Switzerland.

International Federation of Red Cross and Red Crescent Societies (IFRC). 2006c. VCA toolbox and tool reference sheets. IFRC, Geneva, Switzerland.

International Federation of Red Cross and Red Crescent Societies (IFRC). 2006d. Vulnerability and capacity assessment: lessons learned. IFRC, Geneva, Switzerland.

International Federation of Red Cross and Red Crescent Societies (IFRC) and Caribbean Red Cross Societies. 2003. Make that change: community based disaster management. IFRC, Port of Spain, Trinidad and Tobago.

Intergovernmental Panel on Climate Change (IPCC). 2001. Climate change 2001: impacts, adaptation and vulnerability. J. J. McCarthy, O. F. Canziani, N. A. Leary, D. J. Dokken, and K. S. White, editors. Contribution of Working Group II to the Third Assessment Report of the Intergovernmental Panel on Climate Change. Cambridge University Press, Cambridge, UK.

Intergovernmental Panel on Climate Change (IPCC). 2007. Climate change 2007: impacts, adaptation and vulnerability. M. L. Parry, O. F. Canziani, J. P. Palutikof, P. J. van der Linden, and C. E. Hanson, editors. Contribution of Working Group II to the Fourth Assessment Report of the Intergovernmental Panel on Climate Change, Cambridge University Press, Cambridge, UK.

Ionescu, C., R. J. T. Klein, J. Hinkel, K. S. Kavi Kumar, and R. Klein. 2009. Towards a formal framework of vulnerability to climate change. Environmental Modeling and Assessment 14 (1):1-16.

Jäger, J., M. Kok, J. C. Mohamed-Katerere, S. I. Karlsson, M. K. B. Lüdeke, G. D. Dabelko, F. Thomalla, I. de Soysa, M. Chenje, R. Filcak, L. Koshy, M. Long Martello, V. Mathur, A. R. Moreno, V. Narain, and D. Sietz. 2007. Vulnerability of people and the environment: challenges and opportunities. In Global Environment Outlook GEO-4. United Nations Environment Programme, Nairobi, Kenya.

Janssen, M. A. 2007. Synthesis: an update on the scholarly networks on resilience, vulnerability, and adaptation within the human dimensions of global environmental change. Ecology and Society 12(2): 9. [online] URL: http://www.ecologyandsociety.org/ vol12/iss2/art9/.

Janssen, M. A., and E. Ostrom. 2006. Resilience, vulnerability, and adaptation: a cross-cutting theme of the International Human Dimensions Programme on Global Environmental Change. Global Environmental Change 16(3):237-239.

Janssen, M. A., M. L. Schoon, W. Kee, and K. Börner. 2006. Scholarly networks on resilience, vulnerability and adaptation within the human dimensions of global environmental change. Global Environmental Change 16:240-252.

Jasanoff, S. 2003. Technologies of humility: citizen participation in governing science. Minerva 41:223-244. 
Kasperson, R. E., K. Dow, E. R. M. Archer, D. Cáceres, T. E. Downing, T. Elmqvist, S. Eriksen, C. Folke, G. Han, K. Iyengar, C. Vogel, K. A. Wilson, and G. Ziervogel. 2005. Vulnerable people and places. Chapter 6 in Ecosystems and human well-being: current state and trends assessment. Millennium Ecosystem Assessment. Island Press, Washington, D.C., USA.

Keen, M., V. A. Brown, and R. Dyball. 2005. Social learning in environmental management: building a sustainable future. Earthscan Publications, Sterling, Virginia, USA.

Kelly, P. M., and W. M. Adger. 2000. Theory and practice in assessing vulnerability to climate change and facilitating adaptation. Climatic Change $\mathbf{4 7}$ (4):325-352.

Klein, R. J. T., and R. J. Nicholls. 1999. Assessment of coastal vulnerability to climate change. Ambio 28:182-187.

Krasny, M., C. Lundholm, and R. Plummer, editors. 2010. Resilience in Social-Ecological Systems: The Role of Learning and Education. Special Issue Environmental Education Research, in press.

Larsen, R. K., F. Miller, and F. Thomalla. 2009. Vulnerability and recovery from the tsunami: building resilient coastal communities. A synthesis of documented factors contributing to tsunami related vulnerability in Sri Lanka and Indonesia. Research Report, Stockholm Environment Institute, Stockholm, Sweden.

Lavorel, S. 1999. Ecological diversity and resilience of Mediterranean vegetation to disturbance. Diversity and Distributions 5:3-13.

Leichenko, R., and K. O'Brien. 2002. The dynamics of rural vulnerability to global change. Mitigation and Adaptation Strategies for Global Change 7(1):1-18.

Lemos, M. C., E. Boyd, E. L. Tompkins, H. Osbahr, and D. Liverman. 2007. Developing adaptation and adapting development. Ecology and Society 12(2): 26. [online] URL: http://www.ecolog yandsociety.org/vol12/iss2/art26/.
Lemos, M. C., and B. J. Morehouse. 2005. The co-production of science and policy in integrated climate assessments. Global Environmental Change 15:57-68.

McLaughlin, P., and T. Dietz. 2007. Structure, agency and environment: Toward an integrated perspective on vulnerability. Global Environmental Change 39(4):99-111.

Millennium Ecosystem Assessment (MA). 2005. Ecosystems and human well-being: synthesis. Island Press, Washington D.C., USA.

Miller, F., E. de le Rosa, and M. Bohn. 2008a. The challenge of moving from acknowledgement to action: a review of vulnerability to environmental stresses and natural hazards in PRSPs. Stockholm Environment Institute, Stockholm, Sweden.

Miller, F., R. K. Larsen, and F. Thomalla. $2008 b$. Hybrids, bifocals, tipping points and speed dating. report from the resilience-vulnerability colloquium - from theory to practice, from disconnect to synergy in support of sustainable development. Stockholm Environment Institute, Stockholm, Sweden.

Miller, T. R., T. D. Baird, C. M. Littlefield, G. Kofinas, F. Chapin, III, and C. L. Redman. $2008 c$. Epistemological pluralism: reorganizing interdisciplinary research. Ecology and Society 13(2): 46. [online] URL: http://www.ecologyandsociety.org/vol13/iss2/ $\underline{\operatorname{art} 46 / .}$

Nelson, D. R., N. Adger, and K. Brown. 2007. Adaptation to environmental change: contributions of a resilience framework. The Annual Review of Environment and Resources 32:395-419.

Nelson, D. R., and T. J. Finan. 2009. Praying for drought: Persistent vulnerability and the politics of patronage in Ceará, Northeast Brazil. American Anthropologist 111(3):302-316.

Nelson, D. R., M. T. Folhes, and T. J. Finan. 2009. Mapping the road to development: a methodology for inclusion and scaling-up of participation in policy processes. Development in Practice 19 (3):386-395.

Norgaard, R. 1989. The case for methodological pluralism. Ecological Economics 1:37-57. 
Nyström, M., and C. Folke. 2001. Spatial resilience of coral reefs. Ecosystems 4:406-417.

Nyström, M., C. Folke, and F. Moberg. 2000. Coral-reef disturbance and resilience in a human dominated environment. Trends in Ecology and Evolution 15:413-417

O'Brien, K., and R. Leichenko. 2001. The dynamics of vulnerability to global change. IHDP Update, Newsletter of the International Human Dimensions Programme on Global Environmental Change 2:4.

O'Brien, K., T. Quinlan, and G. Ziervogel. 2009. Vulnerability interventions in the context of multiple stressors: lessons from the Southern Africa Vulnerability Initiative (SAVI). Environmental Science and Policy 12:23-32.

Oliver-Smith, A. 1996. Anthropological research on hazards and disasters. Annual Review of Anthropology 25:303-328.

Olsson, P., C. Folke, and T. Hahn. 2004. Socialecological transformation for ecosystem management: the development of adaptive co-management of a wetland landscape in southern Sweden. Ecology and Society 9(4): 2. [online] URL: http://www.ecol ogyandsociety.org/vol9/iss4/art12/.

Olsson, P., L. H. Gunderson, S.R. Carpenter, P. Ryan, L. Lebel, C. Folke, and C. S. Holling. 2006. Shooting the rapids: navigating transitions to adaptive governance of social-ecological systems. Ecology and Society 11(1): 18. [online] URL: http: //www.ecologyandsociety.org/vol11/iss1/art18/.

Osbahr, H., E. Boyd, and P. E. Ericksen. 2007. Resilience, realities and research in African environments. Report of Workshop 18 June 2007, Centre for the Environment, University of Oxford, Oxford, UK.

Osbahr, H., C. Twyman, W. N. Adger, and D. S. G. Thomas. 2008. Effective livelihood adaptation to climate change disturbance: scale dimensions of practice in Mozambique. Geoforum 39:1951-1964.

Ostrom, E. 2007. A diagnostic approach for going beyond panaceas. Proceedings of the National Academy of Sciences 104(39):15181-15187.
Pahl-Wostl, C., M. Craps, A. Dewulf, E. Mostert, D. Tabara, and T. Taillieu. 2007. Social learning and water resources management. Ecology and Society 12(2): 5. [online] URL: http://www.ecology andsociety.org/vol12/iss2/art5/.

Pahl-Wostl, C., E. Mostert, and D. Tabara. 2008. The growing importance of social learning in water resources management and sustainability science. Ecology and Society 13(1): 24. [online] URL: http: //www.ecologyandsociety.org/vol13/iss1/art24/.

Pelling, M. 1999. The political ecology of flood hazard in urban Guyana. Geoforum 30(3):249-261.

Perrings C., K. G. Mäler, C. Folke, C. S. Holling, and B. O. Jansson, editors. 1995. Biological diversity: economic and ecological issues. Cambridge University Press, Cambridge, UK.

Peterson, G., C. R. Allen, and C. S. Holling. 1998. Ecological resilience, biodiversity and scale. Ecosystems 1:6-18.

Prowse, M. 2003. Towards a clearer understanding of 'vulnerability' in relation to chronic poverty. Chronic Poverty Research Paper No. 24. Chronic Poverty Research Centre and the School of Economic Studies/IDPM, University of Manchester, Manchester, UK.

Resilience Alliance. 2009. Assessing and managing resilience in social-ecological systems: a practitioner's workbook, Version 1.0. [online] URL: http://wiki.resalliance.org/index.php/Main Page.

Ramos-Martin, J. 2003. Empiricism in ecological economics: a perspective from complex systems theory. Ecological Economics 46(3):387-398.

Rocheleau, D. 1995. Maps, numbers, text, and context: mixing methods in feminist political ecology. Professional Geographer 47(4):458-466.

Rocheleau, D. 2008. Political ecology in the key of policy: from chains of explanation to webs of relation. Geoforum 39:716-727.

Schneider, S. H., S. Semenov, A. Patwardhan, I. Burton, C. H. D. Magadza, M. Oppenheimer, A. B. Pittock, A. Rahman, J. B. Smith, A. Suarez, and F. Yamin. 2007. Assessing key vulnerabilities and the risk from climate change. In 
Intergovernmental Panel on Climate Change (IPCC). M. L. Parry, O. F. Canziani, J. P. Palutikof, P. J. van der Linden and C. E. Hanson, editors. Climate change 2007: impacts, adaptation and vulnerability. Contribution of Working Group II to the Fourth Assessment Report of the Intergovernmental Panel on Climate Change, Cambridge University Press, Cambridge, UK.

Sen, A. 1981. Poverty and famines: an essay on entitlement and deprivation. Oxford University Press, Oxford, UK.

Stephen, L., and T. E. Downing. 2001. Getting the scale right: a comparison of analytical methods for vulnerability assessment and household level targeting. Disasters 25(2):113-135.

Smith, K. 1992. Environmental hazards: assessing risk and reducing disaster. Routledge, London, UK.

Tschakert, P. 2007. Views from the vulnerable: perceptions on climatic and other stressors in the Sahel. Global Environmental Change 17:381-396.

Thomalla, F., R. K. Larsen, F. Kanji, S. Naruchaikusol, C. Tepa, B. Ravesloot, and A. K. Ahmed. 2009. From knowledge to action: learning to go the last mile. A participatory assessment of the conditions for strengthening the technology community linkages of tsunami early warning systems in the Indian Ocean. Stockholm Environment Institute, Stockholm, Sweden.

Thomas, D. S. G., C. Twyman, H. Osbahr, and B. Hewitson. 2007. Adapting to climate change and variability in southern Africa: farmer responses to intra-seasonal precipitation trends. Climatic Change 83:301-322.

Turner, B. L., II, R. E. Kasperson, P. A. Matson, J. McCarthy, R. W. Corell, L. Christensen, N. Eckley, J. X. Kasperson, A. Luers, M. L. Martello, C. Polsky, A. Pulsipher, and A. Schiller. 2003. A framework for vulnerability analysis in sustainability science. Proceedings of the National Academy of Sciences 100(14):8074-8079.

Twigg, J. 2007. Characteristics of a disasterresilient community: a guidance note. DFID Disaster Risk Reduction Interagency Coordination Group. DFID, London, UK.
United Nations International Strategy for Disaster Reduction (UN ISDR). 2005. Hyogo framework for action 2005-2015: building the resilience of nations and communities to disasters. United Nations International Strategy for Disaster Reduction, Kobe, Japan.

Venton, P., and S. La Trobe. 2008. Linking climate change adaptation and disaster risk reduction. Tearfund/Institute of Development Studies report, UK.

Vogel, C., S. C. Moser, R. E. Kasperson, and G. D. Dabelko. 2007. Linking vulnerability, adaptation, and resilience science to practice: pathways, players, and partnerships. Global Environmental Change 17:349-364.

Walker, B. H., J. M. Anderies, A. P. Kinzig, and P. Ryan, editors. 2006. Exploring resilience in social-ecological systems: comparative studies and theory development. CSIRO Publishing, Collingwood, Victoria, Australia.

Walker, B., C. S. Holling, S. R. Carpenter, and A. Kinzig. 2004. Resilience, adaptability and transformability in social-ecological systems. Ecology and Society 9(2): 5. [online] URL: http://w ww.ecologyandsociety.org/vol9/iss2/art5/.

Walker, B., and D. Salt. 2006. Resilience thinking: sustaining ecosystems in a changing world. Island Press, Washington D.C., USA.

Watts, M. 1983. Silent violence: food, famine and peasantry in northern Nigeria. University of California Press, Berkeley, California, USA.

Watts, M., and H. G. Bohle. 1993. The space of vulnerability: the causal structure of hunger and famine. Progress in Human Geography 17 (1):43-67.

West, C. 2009. Domestic transitions, desiccation, agricultural intensification, and livelihood diversification among rural households on the central plateau, Burkina Faso. American Anthropologist 111 (3):275-288.

Wisner, B., P. Blaikie, T. Cannon, and I. Davis. 2004. At risk: natural hazards, people's vulnerability and disasters. Routledge, London, UK. 
Wisner, B., and H. R. Luce. 1993. Disaster vulnerability: scale, power and daily life. GeoJournal 30:1878-A.

Ziervogel, G., S. Bharwani, and T. E. Downing. 2006a. Adapting to climate variability: pumpkins, people and pumps. Natural Resource Forum 30:294-305.

Ziervogel, G., and A. Taylor. 2008. Feeling stressed: integrating climate adaptation with other priorities in South Africa. Environment 50 (2):32-41.

Ziervogel, G., A. Taylor, T. Takama, F. Thomalla, and C. Quinne. 2006b. Adapting to climate, water and health stresses: insights from Sekhukhune, South Africa. Stockholm Environment Institute, Working Paper, Stockholm, Sweden.

Zou, L., and F. Thomalla. 2008. The causes of social vulnerability to coastal hazards in Southeast Asia. Stockholm Environment Institute, Working Paper, Stockholm, Sweden, ISBN: 978-91-86125-09-7.

[1] The work of researchers within the Risk, Livelihoods and Vulnerability Programme of the Stockholm Environment Institute (www.sei.se) demonstrates this move to greater integration. 